\title{
Optimal scheduling of power systems considering demand response
}

\author{
Zhaohong BIE ${ }^{1}$, Haipeng $\mathrm{XIE}^{1}$, Guowei HU ${ }^{2}$, Gengfeng $\mathrm{LI}^{1}$
}

Abstract A novel optimal scheduling method considering demand response is proposed for power systems incorporating with large scale wind power. The proposed method can jointly dispatch the energy resources and demand side resources to mitigate the fluctuation of load and wind power output. It is noticed in practical operation that, without customer's satisfaction being considered, customers might reject the too frequent or violent demand response all together. In this case, two indices that measure the customer satisfaction are then introduced as constraints to reduce the impact to end-users and avoid extreme demand adjustment. To make the model solvable, a proximate decoupling technique is used to dispose the concave constraint introduced by the customer satisfaction constraints. Results from the case studies show that the proposed model can significantly reduce the operation cost of power system while the demand response meets customer satisfaction. Especially, the total start-up costs of conventional thermal units decreases dramatically due to less startup times. Moreover, compared to the consumption way satisfaction constraint, the payment satisfaction constraint has a heavier influence on the cost.

CrossCheck date: 31 March 2015

Received: 16 September 2014 / Accepted: 1 June 2015/

Published online: 24 July 2015

(C) The Author(s) 2015. This article is published with open access at Springerlink.com

$\bowtie$ Zhaohong BIE

zhbie@mail.xjtu.edu.cn

1 State Key Laboratory of Electrical Insulation and Power Equipment, Department of Electrical Engineering, Xi' an Jiaotong University, Xi'an 710049, China

2 State Grid Jiangsu Economic Research Institute, Nanjing 210000, China
Keywords Optimal scheduling, Wind power, Real-time pricing, Customer satisfaction

\section{Introduction}

Energy crisis and environmental issues are among the challenges threatening the sustainable development of the human society. The renewable resources, especially wind power, have huge potential in tackling these challenges, and over the decades have drawn increasing attention. In recent 20 years, the annual growth worldwide of newly installed wind power capacity maintains a very high speed. By the end of 2013, there are over two hundred thousand wind turbines operating with a total nameplate capacity of $318137 \mathrm{MW}$, among which over 77580 MW is installed in China and 61100 MW in the US [1]. Though the wind power provides clean and economical energy [2], it arouses operation puzzles. One of the operation puzzles is that the stochastic and intermittent nature complicates the scheduling of conventional thermal unit. In addition to operation technological challenge, the scheduling puzzle is apt to offset the financial benefits. Therefore, it draws more and more researchers' attention to enhancing the economy of the wind power systems via optimal scheduling.

There are already abundant studies on unit commitment and dispatch for power systems containing wind power. Unit commitment for systems with large-scale wind power was firstly studied more than 20 years ago [3-5]. In these studies, practical and concise power control algorithms were proposed. However, they are too simple to apply in current complex power grids. In [6], a new simulation method that can fully assess the impacts of large-scale wind power on system operations was proposed and the impacts were analyzed with the Dutch power system. Due to the forecast error, the effectiveness of unit commitment lessens. In [7], a scenario tree tool was developed which allows forecast error statistics to be 
altered and facilitates the study of how these statistics impact on unit commitment and system operation. In [8], a novel unit commitment model was proposed to handle the stochastic nature of wind power. In the model, day-ahead and intra-day two stage stochastic optimization was employed. A fuzzyoptimization approach was introduce in [9] to solving the generation scheduling problem with consideration of wind and solar energy systems. In the presented model, wind speed and solar radiation errors can be taken into account using fuzzy sets. But the above mentioned studies focused solely on the scheduling of thermal units to fit the randomness of load and wind power but neglect demand side participation. Reference [10] assessed the value of demand side for wind integration in unit commitment. Multi-stage robust unit commitment approach was proposed to consider the uncertainties of wind and demand response in [11]. Compared with the previous research, this study took the thermal units and demand response into account and dealt with the uncertainties effectively. In addition, numerous studies potently promoted unit commitment considering demand response [12-14]. In terms of similar studies, critical peak pricing (CPP), one of the other popular demand response program, was scheduled in the multi-stage unit commitment with wind power [15] and the similar studies was conducted in [16].

Real-time pricing (RTP), one of the price-based demand response means, can guide the power customers' consumption behavior with the price signal. In this paper, RTP participates in the scheduling to promote the economic operation. Hereinafter, the RTP is generally referred to as demand response. On one hand, demand response brings economic benefits for both power suppliers and customers, but on the other hand it sometimes affects the convenience of the customers. Therefore, customer satisfaction is introduced into the optimal scheduling to avoid extreme demand response. The concept of customer satisfaction was used in many areas [17] as well as in research on power systems [18]. This paper aims to build customer satisfaction constraints to restraint the demand response and study the impacts of the satisfaction indices on the optimal operation. The determination of satisfaction indices criteria is the compromise of economy and comfort level, which is beyond the scope of this paper.

This paper is organized as follows. Demand response model for RTP is built in Section 2. Then two customer satisfaction indices are introduced in Section 3. In Section 4, an optimal scheduling model is proposed for power systems including significant wind power penetration. Case studies are conducted in Section 5. Conclusions are drawn in Section 6.

\section{Demand response model}

There are four common methods to model the response of customers' power consumption to the prices, which comprise: (1) price elasticity coefficient, (2) based on consumer psychology principle, (3) based on principle of statistics, (4) based on the exponential function fitting. Within the four methods, the first is the popular, effective and concise. Thus the demand response in this paper is based on price elastic coefficient.

\subsection{Price elasticity coefficient}

Price elasticity of demand is a term in economics often used when discussing price sensitivity. In this model, electricity price elasticity matrix is used to present the demand variation as the consequence of the price adjustment. The formula for calculating price elasticity is:

$\varepsilon=\frac{\Delta q / q}{\Delta p / p}$

where $\Delta q$ and $\Delta p$ are the increments of the electricity consumption $q$ and the price $p$ in percentage respectively.

Generally, price elasticity of demand can be divided into single time interval and multi time intervals response. Single-time interval response only considers the influence on the current time interval, so it is only able to adjust the electricity consumption in the corresponding interval and not to dispatch the load between time intervals. Multi time intervals response depicts the reality better because customers could adjust their consumption plan in any time interval based on the price adjustment, and it is used in this model. In the multi time intervals response model, electricity elasticity coefficients can be classified into selfelasticity coefficient and mutual elasticity coefficient. According to the definition in (1), the definition of selfelasticity coefficient and mutual elasticity coefficient can be formulated as (2) and (3).

$\varepsilon_{i, i}=\frac{\Delta q_{i} / q_{i}}{\Delta p_{i} / p_{i}}$

$\varepsilon_{i, j}=\frac{\Delta q_{i} / q_{i}}{\Delta p_{j} / p_{j}}$

where the subscripts $i$ and $j$ are the $i^{\text {th }}$ and $j^{\text {th }}$ interval respectively.

\subsection{Demand response model}

The model for the demand response can be expressed as

$\left[\begin{array}{c}\Delta q_{1} / q_{1} \\ \Delta q_{2} / q_{2} \\ \vdots \\ \Delta q_{n} / q_{n}\end{array}\right]=\boldsymbol{E}\left[\begin{array}{c}\Delta p_{1} / p_{1} \\ \Delta p_{2} / p_{2} \\ \vdots \\ \Delta p_{n} / p_{n}\end{array}\right]$ 
where $\boldsymbol{E}=\left(\begin{array}{ccc}\varepsilon_{11} & \cdots & \varepsilon_{1 n} \\ \vdots & \ddots & \vdots \\ \varepsilon_{n 1} & \cdots & \varepsilon_{n n}\end{array}\right)$ is the electricity elasticity matrix.

\section{Customer satisfaction}

Customer satisfaction is a concept in power marketing. The day-ahead load profile and electricity prices will alter after the demand response is introduced into unit commitment considering wind power. The calculated optimal results may cause unwanted load shedding and impact the interest of customers if the unit commitment does not consider the customer satisfaction. If customer satisfaction is ignored, customers may reject the demand response and then it is apt to fail to utilize wind power in a more economical way with the customers' interaction. As is mentioned in [19], two customer satisfaction indices, consumption way index and payment index, are presented in this paper. In the proposed unit commitment model, the two indices are considered as constraints.

The consumption way index $m$ can be formulated as (5).

$m=1-\frac{\sum_{t=1}^{24}\left|\Delta q_{t}\right|}{\sum_{t=1}^{24} q_{t}}$

where $\sum_{t=1}^{24}\left|\Delta q_{t}\right|$ is the total power consumption variation after the price optimization, and $\sum_{t=1}^{24} q_{t}$ is the total power consumption before price optimization.

The payment index $s$ can be formulated as (6).

$s=1-\frac{\sum_{t=1}^{24} \Delta L_{t}}{\sum_{t=1}^{24} L_{t}}$

where $\sum_{t=1}^{24} \Delta L_{t}$ is the total payment decrement after the price optimization, and $\sum_{t=1}^{24} L_{t}$ is the total payment of the customers before price optimization.

Obviously, the larger $m$ and $s$ will satisfy the customers more.

\section{Unit commitment model}

\subsection{Objective}

The objective of the proposed model is to minimize the operation cost of the whole system, which contains generation cost and start-up cost. Generation cost can be depicted by linear function, quadratic function or piecewise function, and quadratic function is adopted in this model due to its accuracy and differentiability. The start-up cost also contains the shut-down cost for easier expression. As the wind power production consumes no costly energy, the wind power production cost is ignored. Therefore, the objective can be formulated as

$\min F=\sum_{t=1}^{T} \sum_{i=1}^{I}\left[\begin{array}{c}z_{i}(t) C_{i}\left(P_{i}(t)\right) \\ +z_{i}(t)\left(1-z_{i}(t-1)\right) S_{i}\end{array}\right]$

where $F$ is the total operation cost of the system; $T$ is the number of time intervals in the studied period; $I$ is the number of units in the system; $P_{i}(t)$ is the active power of unit $i$ in the time interval $t ; z_{i}(t)$ is the state of unit $i$ in the time interval $t, z_{i}(t)=1$ denotes the unit is up and $z_{i}(t)=0$ denotes the unit is down; $S_{i}$ is the start-up cost of unit $i$; and $C_{i}\left(P_{i}(t)\right)$ is the operation cost of unit $i$ in the time interval $t$. It can be indicated as

$C_{i}\left(P_{i}(t)\right)=a_{i} P_{i}^{2}+b_{i} P_{i}+c_{i}$

where $a_{i}, b_{i}, c_{i}$, are constant parameters for the operation cost of a unit.

\subsection{Constraints}

1) Power balance

$\sum_{i=1}^{I} P_{i}(t)+P_{\mathrm{w}}(t)=P_{\mathrm{d}}(t), t=1,2, \cdots, T$

where $P_{\mathrm{w}}(t)$ is the forecasted wind power output in time interval $t$, and $P_{\mathrm{d}}(t)$ is the load of the power system in the time interval $t$. It is noted that the load is variable and influence by price compared with conventional unit commitment.

2) Output of unit constraint

$\underline{P}_{i} \leq P_{i} \leq \bar{P}_{i}$

where $\overline{P_{i}}$ and $\underline{P}_{i}$ are upper and lower bounds of the unit $i$ respectively.

3) Ramp constraints

$P_{i}(t)-P_{i}(t-1) \leq r_{\mathrm{u}, i} \cdot T_{60}$

$P_{i}(t-1)-P_{i}(t) \leq r_{\mathrm{d}, i} \cdot T_{60}$

where $r_{\mathrm{u}, i}$ and $r_{\mathrm{d}, i}$ are the maximum ramp up and ramp down power of the unit $i$ respectively (MW/min). $T_{60}$ denotes $60 \mathrm{~min}$.

4) Operation time constraints

$T_{i}^{\mathrm{on}} \geq M_{\mathrm{UT}, i}$

$T_{i}^{\text {off }} \geq M_{\mathrm{DT}, i}$

where $T_{i}^{\text {on }}$ and $T_{i}^{\text {off }}$ are continuous running time and continuous stoppage time respectively, and $M_{\mathrm{UT}, i}$ and $M_{\mathrm{DT}, i}$ 
are minimum running time and minimum stoppage time respectively.

5) Spinning reserve constraints

$\sum_{i=1}^{I} \min \left(z_{i}(t) \overline{P_{i}}-z_{i}(t) P_{i}(t), U_{\mathrm{R}, i}\right) \geq R(t)+R_{\mathrm{W}}(t)$

where $U_{\mathrm{R}, i}$ is the upper bound of the active power of unit $i$, $U_{\mathrm{R}, i}=r_{\mathrm{u}, i} \cdot T_{60} ; R(t)$ is the spinning reserve in time interval $t$ without wind power; and $R_{\mathrm{w}}(t)$ is the additional reserve needed caused by the integration of wind power.

6) Customer satisfaction constraints

$m \geq N_{\text {dexm }}$

$s \geq N_{\text {dexs }}$

In (16) and (17), $N_{\text {dexm }}$ and $N_{\text {dexs }}$ are the lower bounds of consumption way and payment satisfaction respectively.

7) Demand power constraints

$P_{\mathrm{d} \min } \leq P_{\mathrm{d}}(t) \leq P_{\mathrm{d} \max }$

where $P_{\mathrm{d} \text { max }}$ and $P_{\mathrm{d} \text { min }}$ are the upper and lower bounds of demand respectively.

8) Price constraints

$p_{\min } \leq p(t) \leq p_{\max }$

where $p(t)$ is the price in time interval $t$ after optimization; $p_{\max }$ and $p_{\text {min }}$ are the upper and lower bounds of electricity price respectively.

9) Demand response constraint

$\left[\begin{array}{c}\Delta q_{1} / q_{1} \\ \Delta q_{2} / q_{2} \\ \vdots \\ \Delta q_{n} / q_{n}\end{array}\right]=\boldsymbol{E}\left[\begin{array}{c}\Delta p_{1} / p_{1} \\ \Delta p_{2} / p_{2} \\ \vdots \\ \Delta p_{n} / p_{n}\end{array}\right]$

where $q_{t}=p_{\mathrm{d}}(t) \cdot T$ is the power demand in time interval $t$ before optimization; $\Delta q_{t}$ is the demand variation after optimization; $p_{t}$ is the price in the time interval $t$ before optimization; $\Delta p_{t}$ is the price variation after optimization, and $\boldsymbol{E}$ is the price elasticity matrix.

10) Security constraint

$F_{i, t}<F_{i}^{\max }$

where $F_{i}^{\max }$ and $F_{i, t}$ is the power flow limit and the power flow at time $t$ of the $i^{\text {th }}$ transmission line respectively. DC power flow model is applied in this paper and the detailed implement can be found in [20].

Compared with the conventional unit commitment model, the proposed model considers customer demand constraints (16-20). Moreover, the electricity prices and the demands are variable to cope with the integration of wind power and improve the economical efficiency of the power system operation. The proposed model presents a complex mixed integer programming problem that is difficult to solve. In this paper, the complex optimization problem is solved with the IBM ILOG CPLEX Optimizer.

It is noted that the customer payment satisfaction index can lead to concave constraint which makes the optimization problem unsolvable. A proximate decoupling method is applied to linearize the constraint. The approximation can be formulated as (21). After the approximation, price variables and power variables are decoupled and the index is linearized. As such, the approximation will impact on the accuracy of the index. However, the index still functions because the modified expression is also capable of characterizing the customer payment satisfaction, which is what we really care about.

$$
\begin{aligned}
& s=1-\frac{\sum_{t=1}^{24} \Delta L_{t}}{\sum_{t=1}^{24} L_{t}}=1-\frac{\sum_{t=1}^{24}\left(\sum_{i=1}^{I} P_{i}(t) \cdot p_{t}-\sum_{i=1}^{I} P_{i}^{0}(t) \cdot p_{t}^{0}\right)}{\sum_{t=1}^{24}\left(\sum_{i=1}^{I} P_{i}^{0}(t) \cdot p_{t}^{0}\right)} \\
& \approx 1-\frac{\sum_{t=1}^{24}\left(\frac{1}{2} \sum_{i=1}^{I} P_{i}(t) \cdot p_{t}^{0}+\frac{1}{2} \sum_{i=1}^{I} P_{i}^{0}(t) \cdot p_{t}-\sum_{i=1}^{I} P_{i}^{0}(t) \cdot p_{t}^{0}\right)}{\sum_{t=1}^{24}\left(\sum_{i=1}^{I} P_{i}^{0}(t) \cdot p_{t}^{0}\right)}
\end{aligned}
$$

where $p_{i}(t)$ is the output of the $i^{\text {th }}$ unit in the time interval $t$, and $p_{t}$ is the electricity price in the time interval $t$. The variables before optimization are labeled by the superscript 0 .

\section{Case Studies}

\subsection{Introduction of the test system}

Modified IEEE RTS-79 test system [21] with 26 conventional units and 2 wind farms is studied in this paper. The major parameters of the conventional units are shown in Table 1. The wind farms are integrated in Bus 17 and Bus 22. The original load profile is shown in Fig. 1, which is derived from a typical load profile in South China. The price elasticity matrix data are derived from [22]. The selfelasticity coefficient and mutual elasticity coefficient are -0.2 and 0.033 in this paper. The original electricity price is $30 \mathrm{\$} / \mathrm{MWh}$.

It is assumed that there are 100 wind turbines in each wind farm. The capacity of each wind turbine is $2 \mathrm{MW}$ and thus the total capacity of each wind farm is $200 \mathrm{MW}$. The dayahead forecasted wind power profiles are shown in Fig. 1.

\subsection{Without customer satisfaction constraints}

The unit commitments with demand response and without demand response are studied respectively. The 
Table 1 Parameters of the conventional units

\begin{tabular}{|c|c|c|c|c|c|}
\hline No. & $\begin{array}{l}P_{\max } / P_{\min } \\
(\mathrm{MW})\end{array}$ & $c / b / a$ & $\begin{array}{l}\text { min_up/ } \\
\text { min_dn (h) }\end{array}$ & $\begin{array}{l}\text { Start } \\
\text { cost }(\$)\end{array}$ & $\begin{array}{l}\text { Initial } \\
\text { status (h) }\end{array}$ \\
\hline 1 & $400 / 100$ & $311.9102 / 7.5031 / 0.0019$ & $8 / 5$ & 1000 & 10 \\
\hline 2 & $400 / 100$ & $310.0021 / 7.4921 / 0.0019$ & $8 / 5$ & 1000 & 10 \\
\hline 3 & $350 / 140$ & $177.0575 / 10.8616 / 0.0015$ & $8 / 5$ & 600 & 10 \\
\hline 4 & $197 / 68.95$ & $260.1760 / 23.200 / 0.0026$ & $5 / 4$ & 400 & -4 \\
\hline 5 & $197 / 68.95$ & $259.6490 / 23.100 / 0.0026$ & $5 / 4$ & 400 & -4 \\
\hline 6 & $197 / 68.95$ & $259.1310 / 23.000 / 0.0026$ & $5 / 4$ & 400 & -4 \\
\hline 7 & $155 / 54.25$ & $143.5972 / 10.7583 / 0.0049$ & $5 / 3$ & 300 & 5 \\
\hline 8 & $155 / 54.25$ & $143.3719 / 10.7367 / 0.0048$ & $5 / 3$ & 300 & 5 \\
\hline 9 & $155 / 54.25$ & $143.0288 / 10.7154 / 0.0047$ & $5 / 3$ & 300 & 5 \\
\hline 10 & $155 / 54.25$ & $142.7348 / 10.6940 / 0.0046$ & $5 / 3$ & 300 & 5 \\
\hline 11 & $100 / 25.00$ & $218.7752 / 18.2 / 0.0060$ & $4 / 2$ & 140 & -3 \\
\hline 12 & $100 / 25.00$ & $218.3350 / 18.1 / 0.0061$ & $4 / 2$ & 140 & -3 \\
\hline 13 & $100 / 25.00$ & $217.8952 / 18.0 / 0.0062$ & $4 / 2$ & 140 & -3 \\
\hline 14 & $76 / 15.2$ & $81.6259 / 13.4073 / 0.0093$ & $3 / 2$ & 100 & 3 \\
\hline 15 & $76 / 15.2$ & $81.4641 / 13.3805 / 0.0091$ & $3 / 2$ & 100 & 3 \\
\hline 16 & $76 / 15.2$ & $81.2980 / 13.3538 / 0.0089$ & $3 / 2$ & 100 & 3 \\
\hline 17 & $76 / 15.2$ & $81.1364 / 13.3272 / 0.0088$ & $3 / 2$ & 100 & 3 \\
\hline 18 & $20 / 4$ & $118.8206 / 37.8896 / 0.0143$ & $1 / 1$ & 40 & -1 \\
\hline 19 & $20 / 4$ & $118.4576 / 37.7770 / 0.0136$ & $1 / 1$ & 40 & -1 \\
\hline 20 & $20 / 4$ & $118.1083 / 37.6637 / 0.0126$ & $1 / 1$ & 40 & -1 \\
\hline 21 & $20 / 4$ & $117.7551 / 37.5510 / 0.0120$ & $1 / 1$ & 40 & -1 \\
\hline 22 & $12 / 2.4$ & $24.8882 / 26.0611 / 0.0285$ & $4 / 2$ & 10 & -2 \\
\hline 23 & $12 / 2.4$ & $24.7605 / 25.9318 / 0.0284$ & $4 / 2$ & 10 & -2 \\
\hline 24 & $12 / 2.4$ & $24.6382 / 25.8027 / 0.0280$ & $4 / 2$ & 10 & -2 \\
\hline 25 & $12 / 2.4$ & $24.4110 / 25.6753 / 0.0265$ & $4 / 2$ & 10 & -2 \\
\hline 26 & $12 / 2.4$ & $24.3891 / 25.5472 / 0.0253$ & $4 / 2$ & 10 & -2 \\
\hline
\end{tabular}

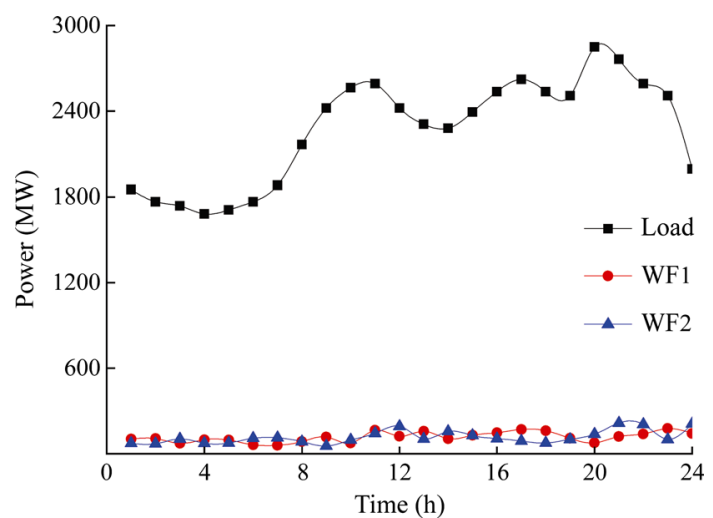

Fig. 1 Original profile of system load and forecasting wind generations

results comparison of the two operation scenarios is shown in Table 2.

As shown in Table 2, after the demand response is implemented, the total operation cost of the system decreases by $\$ 33720$ (5.4\%). In detail, the start-up cost and fuel cost both decrease and the start-up cost decreases dramatically in the case of the descending percentage. The reason of the cost drop is clear. In the study, demand response adjusts the customer demand to overcome the intermittent of the wind power, which smoothes the power demand of the system from the conventional units. Smooth demand profile means less start-up times and less start-up cost. Furthermore, less start-up times indicate more opportunities to utilize the efficient units because an efficient unit cannot start up immediately once it shuts down. Thus, the total fuel cost also decreases.

\subsection{Considering demand response and customer satisfaction}

After demand response participates in the unit commitment, the new scheduling pattern will jointly employ the power sources and demand side resources to utilize wind power and meet the demand. The load profile and price profile after optimization under various conditions are shown in Fig. 2 and Fig. 3 respectively. 
Table 2 Optimization results comparison between the system with and without demand response

\begin{tabular}{llcc}
\hline & Start-up cost $(\$)$ & Fuel cost $(\$)$ & Total cost (\$) \\
\hline Without DR & 24640 & 599647 & 624287 \\
With DR & 15200 & 575367 & 590567 \\
Difference & 9440 & 24280 & 33720 \\
\hline
\end{tabular}

As shown in Fig. 2 and Fig. 3, without customer satisfaction constraints, the load profile is smooth while the price varies significantly. Actually the drastic adjustment does not prove effective because the coefficient of price elasticity becomes large for exaggerated price variation. After the customer satisfaction constraints are considered, the price and load profiles present acceptable variation. Fig. 2 and Fig. 3 show that the consumption way satisfaction and payment satisfaction both impact the load profiles and price profiles. In Fig. 2, the load profiles under various payment satisfaction constraints present a greater difference than that under various consumption way satisfaction constraints. In Fig. 3, the impact of payment satisfaction constraints is even more obvious than that of consumption way satisfaction constraints. From the definitions in (5) and (6), it can be concluded that less payment means shifting more demand to hours with lower price while more consumption way satisfaction means less energy consumption to be shifted. It is noted that the

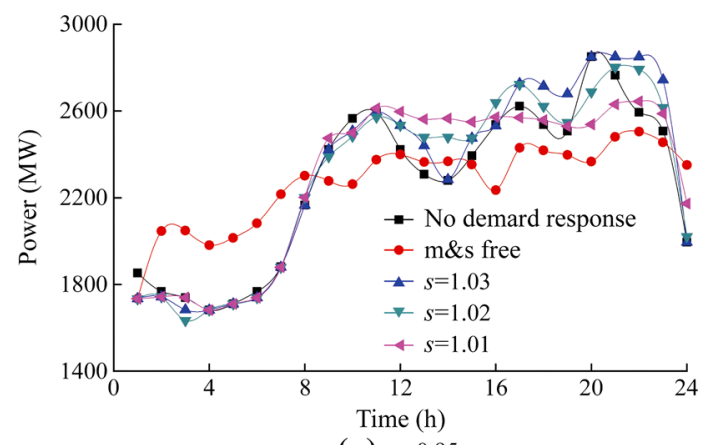

(a) $m=0.95$

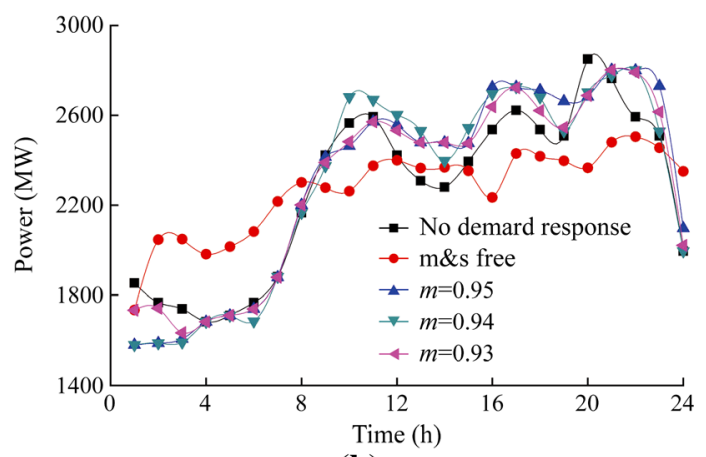

(b) $s=1.03$

Fig. 2 Load profiles in different denard response scenarios

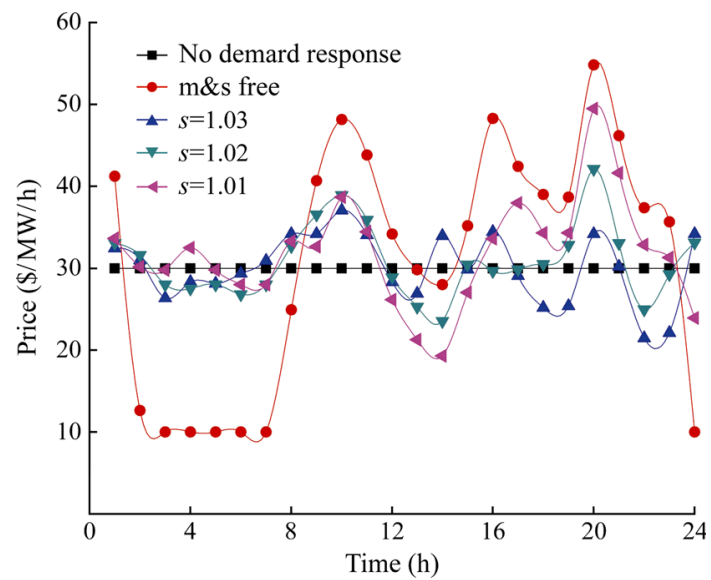

(a) $m=0.95$

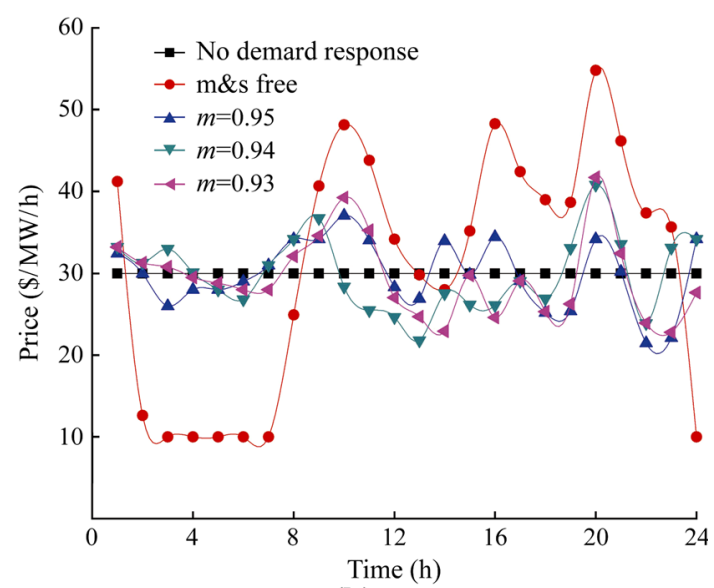

(b) $s=1.03$

Fig. 3 Price profiles in different scenarios

payment is related to both price and load while the consumption way is only related to the load. The shift of load is achieved by the variation of the price. The variation of the price totally impairs the shift of load. Therefore, more efforts are needed to meet the payment constraints. That is why the payment constraints impact constraints more obviously.

The optimal results of the operation cost under different satisfaction combinations are shown in Table 3.

Distinctly, payment satisfaction constraints have a greater influence on the cost than consumption way satisfaction constraints according to the results in Table 3. That difference is consistent to the above analysis of the customer satisfaction influences. The results in Table 2 and Table 3 indicate that the operation cost rises and even becomes larger than the scenarios without demand response as the customer satisfaction indices constraints increase. In the real operation, a couple of appropriate customer satisfaction indices should be established by the market regulator to balance the benefits of customers and power suppliers. 
Table 3 Total operation cost in different scenarios

\begin{tabular}{llll}
\hline$N_{\text {dexm }}$ & \multicolumn{3}{l}{ Total operation cost $(\$)$} \\
\cline { 2 - 4 } & $N_{\text {dexs }}=1.01$ & $N_{\text {dexs }}=1.02$ & $N_{\text {dexs }}=1.03$ \\
\hline 0.93 & 609845 & 618355 & 621441 \\
0.94 & 609943 & 618742 & 625107 \\
0.95 & 610892 & 622649 & 629743 \\
\hline
\end{tabular}

\section{Conclusions}

This paper presents a scheduling method where the power sources and demand side resources are jointly employed to meet the demand and exploit wind power. Moreover, the customer satisfactions are introduced to take the customers' interest into account. The correctness and validity of this model are verified by the case study conducted on the IEEE RTS-79 test systems. From the case study, the following conclusions can be drawn.

1) When the unit commitment considers demand response, the power sources and demand side resources are both programmable to meet the power balance. The scheduling model can reduce the unit start-up times and hence it can reduce the operation cost of the power systems dramatically. Thus, the consideration of demand response can obviously improve the economy.

2) The consideration of customer satisfaction is necessary. The operation cost of the power systems varies upon different customer satisfaction levels. The operation cost is more sensitive to payment satisfaction index than consumption way satisfaction.

Acknowledgment This work was supported by Specialized Research Fund for the Doctoral Program of Higher Education SRFDP of China (No: 20130201130001), the Fundamental Research Funds for the Central Universities and Independent research project of State Key laboratory of Electrical Insulation and Power Equipment (No: EIPE14106).

Open Access This article is distributed under the terms of the Creative Commons Attribution 4.0 International License (http://creativecommons.org/licenses/by/4.0/), which permits unrestricted use, distribution, and reproduction in any medium, provided you give appropriate credit to the original author(s) and the source, provide a link to the Creative Commons license, and indicate if changes were made.

\section{References}

[1] 2014-2019 Chinese wind power industry research and investment prospects panoramic assessment report. R223695, ZhiYan.org, Beijing, China 2003 (in Chinese)
[2] Wang CX, Lu ZX, Qiao Y (2013) A consideration of the wind power benefits in day-ahead scheduling of wind-coal intensive power systems. IEEE Trans Power Syst 28(1):236-245

[3] Contaxis GC, Kabouris J (1991) Short term scheduling in a wind/diesel autonomous energy system. IEEE Trans Power Syst 6(3):1161-1167

[4] Schlueter RA, Park GL, Lotfalian M et al (1983) Modification of power system operation for significant wind generation penetration. IEEE Trans Power Appar Syst 102(1):153-161

[5] Schlueter RA, Park GL, Reddoch TW et al (1985) A modified unit commitment and generation control for utilities with large wind generation penetrations. IEEE Trans Power Appar Syst 104(7):1630-1636

[6] Ummels BC, Gibescu M, Pelgrum E et al (2007) Impacts of wind power on thermal generation unit commitment and dispatch. IEEE Trans Energy Convers 22(1):44-51

[7] Lowery C, O'Malley M (2012) Impact of wind forecast error statistics upon unit commitment. IEEE Trans Sustain Energy 3(4):760-768

[8] Tuohy A, Meibom P, Denny E et al (2009) Unit commitment for systems with significant wind penetration. IEEE Trans Power Syst 24(2):592-601

[9] Liang RH, Liao JH (2007) A fuzzy-optimization approach for generation scheduling with wind and solar energy systems. IEEE Trans Power Syst 22(4):1665-1674

[10] De Jonghe C, Hobbs BF, Belmans R (2014) Value of price responsive load for wind integration in unit commitment. IEEE Trans Power Syst 29(2):675-685

[11] Zhao CY, Wang JH, Watson JP et al (2013) Multi-stage robust unit commitment considering wind and demand response uncertainties. IEEE Trans Power Syst 28(3):2708-2717

[12] Wang QF, Wang JH, Guan YP (2013) Stochastic unit commitment with uncertain demand response. IEEE Trans Power Syst 28(1):562-563

[13] Aghaei J, Alizadeh MI (2013) Critical peak pricing with load control demand response program in unit commitment problem. IET Gener Transm Distrib 7(7):681-690

[14] Wang F, Wang JH, Guan YP (2013) Price-based unit commitment with wind power utilization constraints. IEEE Trans Power Syst 28(3):2718-2726

[15] Zhang XX (2014) Optimal scheduling of critical peak pricing considering wind commitment. IEEE Trans Sustain Energy 5(2):637-645

[16] De Jonghe C, Hobbs BF, Belmans R (2012) Optimal generation mix with short-term demand response and wind penetration. IEEE Trans Power Syst 27(2):830-839

[17] Liu X, Zhang WJ, Tu YL et al (2008) An analytical approach to customer requirement satisfaction in design specification development. IEEE Trans Eng Manag 55(1):94-102

[18] Sullivan MJ, Noland Suddeth B, Vardell T et al (1996) Interruption costs, customer satisfaction and expectations for service reliability. IEEE Trans Power Syst 11(2):989-995

[19] Ding W, Yuan JH, Hu ZG (2005) Time-of-use price decision model considering users reaction and satisfaction index. Autom Electr Power Syst 29(20):10-14 (in Chinese)

[20] Wang SJ, Shahidehpour SM, Kirschen DS et al (1995) Shortterm generation scheduling with transmission and environmental constraints using an augmented Lagrangian relaxation. IEEE Trans Power Syst 10(3):1294-1301

[21] Chairman PF, Bhavaraju MP, Biggerstaff BE et al (1979) IEEE reliability test system: a report prepared by the Reliability Test System Task Force of the Application of Probability Methods Subcommittee. IEEE Trans Power Appar Syst 98(6):2047-2054

[22] Kirschen DS, Strbac G, Cumperayot P et al (2000) Factoring the elasticity of demand in electricity prices. IEEE Trans Power Syst 15(2):612-617 
Zhaohong BIE received the B.S. and M.S. degrees from the Electric Power Department of Shandong University, Jinan, China, in 1992 and 1994, respectively, and the Ph.D. degree from Xi'an Jiaotong University, Xi'an, China, in 1998. Currently, she is a Professor in the State Key Laboratory of Electrical Insulation and Power Equipment and the School of Electrical Engineering, Xi'an Jiaotong University. Her main interests and research fields are power system planning and reliability evaluation as well as the integration of the renewable energy.

Haipeng XIE received the B.S. degree from the Electric Power Department of Xi' an Jiaotong University, Xi'an, China, in 2012. He is currently pursuing the $\mathrm{Ph}$.D. degree at Xi' an Jiaotong University. His research interest is the optimal scheduling of power systems with large scale wind power.

Guowei HU received the B.S. and M.S. degrees from the Electric Power Department of Xian Jiaotong University, Xian, China, in 2010 and 2013, respectively. He is currently employed by State Grid Jiangsu Economic Research Institute. His research interests include the unit commitment considering the integration of large scale wind power.

Gengfeng LI received the B.S. and Ph.D. degrees from the Electric Power Department of Xian Jiaotong University, Xi' an; China, in 2008 and 2014, respectively. He is currently a lecturer in the School of Electrical Engineering, Xi'an Jiaotong University. His research interests include the distribution system reliability evaluation and the dispatching and control of micro-grids. 